\title{
Crustal structure and high-resolution Moho topography across the Rwenzori region (Albertine rift) from P-receiver functions
}

\author{
Michael Gummert ${ }^{1}$, Michael Lindenfeld ${ }^{1}$, Ingo Wölbern ${ }^{1}$, \\ Georg Rümpker ${ }^{1}$, Kasereka Celestin² \& Arthur Batte $^{3}$ \\ ${ }^{1}$ Institut für Geowissenschaften, Goethe-Universität Frankfurt, Frankfurt, Germany \\ ${ }^{2}$ Goma Volcano Observatory, Goma, Democratic Republic of Congo \\ ${ }^{3}$ Department of Geology, Makerere University, Kampala, Uganda
}

Example of an Н-қ stacking diagram

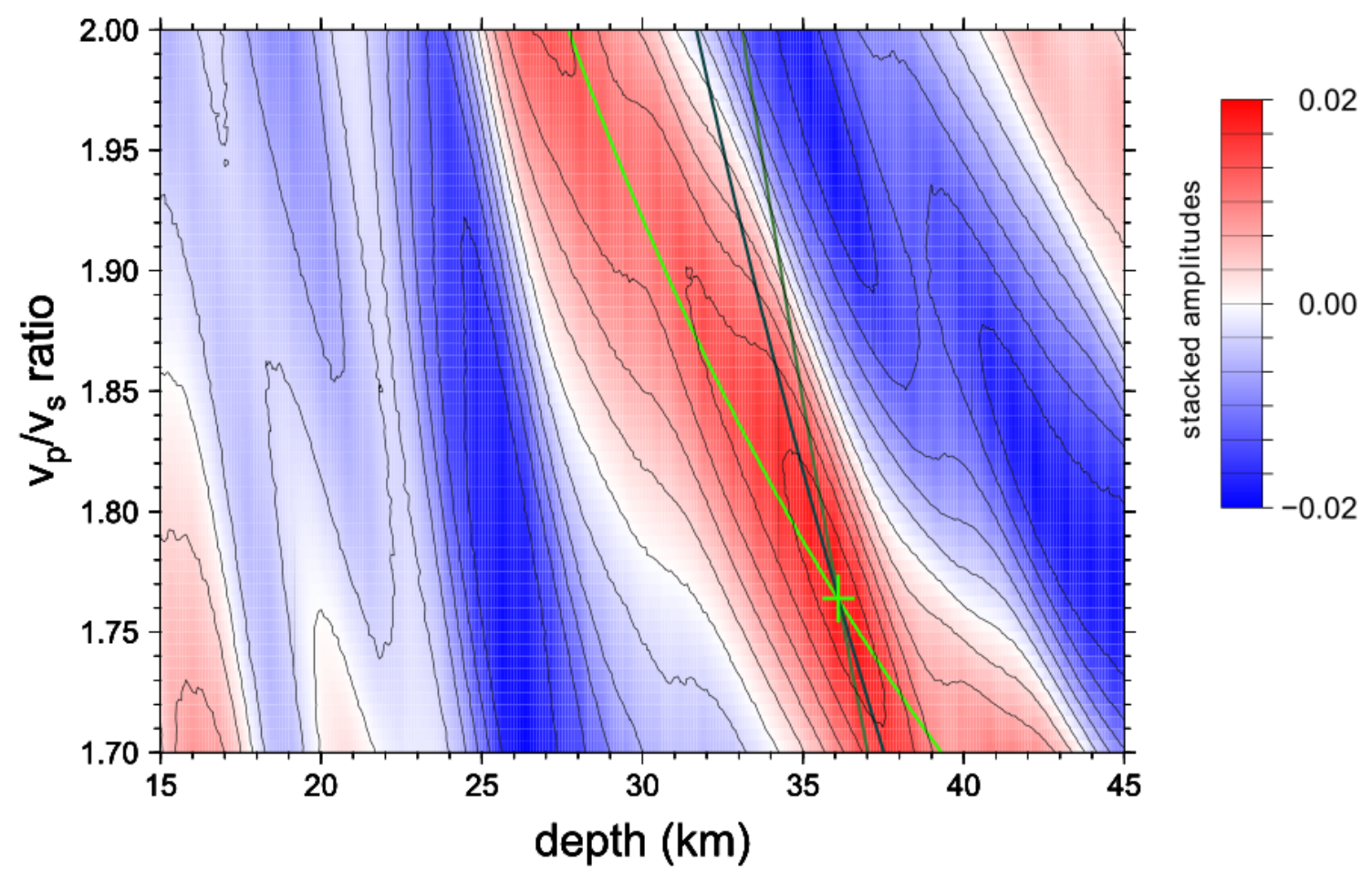

Figure S1: Result of Н-қ stacking at station C02 using the method of Zhu and Kanamori (2000). The derived values for Moho depth and $\mathrm{v}_{\mathrm{p}} / \mathrm{v}_{\mathrm{s}}$ ratio are marked by a green cross. The superimposed green lines indicate theoretical delay times for the Moho conversions Ps (light green), PpPs (green), and PpSs (dark green). 


\section{Analysis of direct converted and multiple phases}

This section describes the analysis performed to identify direct converted and multiple phases in the receiver functions.

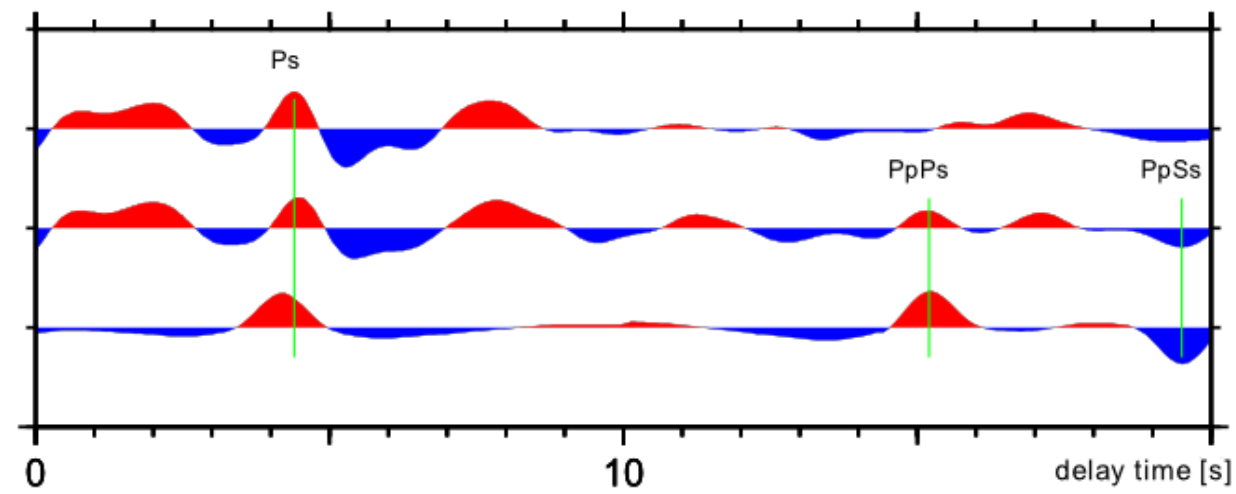

Figure S2: Moveout corrections and forward modelling of P-receiver functions. The moveout effect associated with different epicentral distances requires delay time corrections in order to coherently stack the signals of different receiver-function traces. We used an average P-wave slowness of $6.4 \mathrm{sec} /{ }^{\circ}$ that corresponds to an epicentral distance of $67^{\circ}$ (IASP91 velocity model; Kennett \&Engdahl, 1991). The moveot effect for the direct converted (Ps) phase differs from that of the multiple phases (PpPs and PpSs). Therefore, in order to correctly identify direct converted and multiple phases, moveout corrections are applied separately for each of them.Figure S2 shows exemplary data from station C01: (top) stacked receiver functions withmoveout correction for direct converted phases, (middle) stacked receiver functions with moveout correction for multiple phases, (bottom) synthetic receiver function. The direct converted phase (Ps) and its multiples (PpPs and PpSs) are identified in the receiver functions by comparing amplitudes of the top and middle traces with the theoretical results (as indicated by the green lines). 


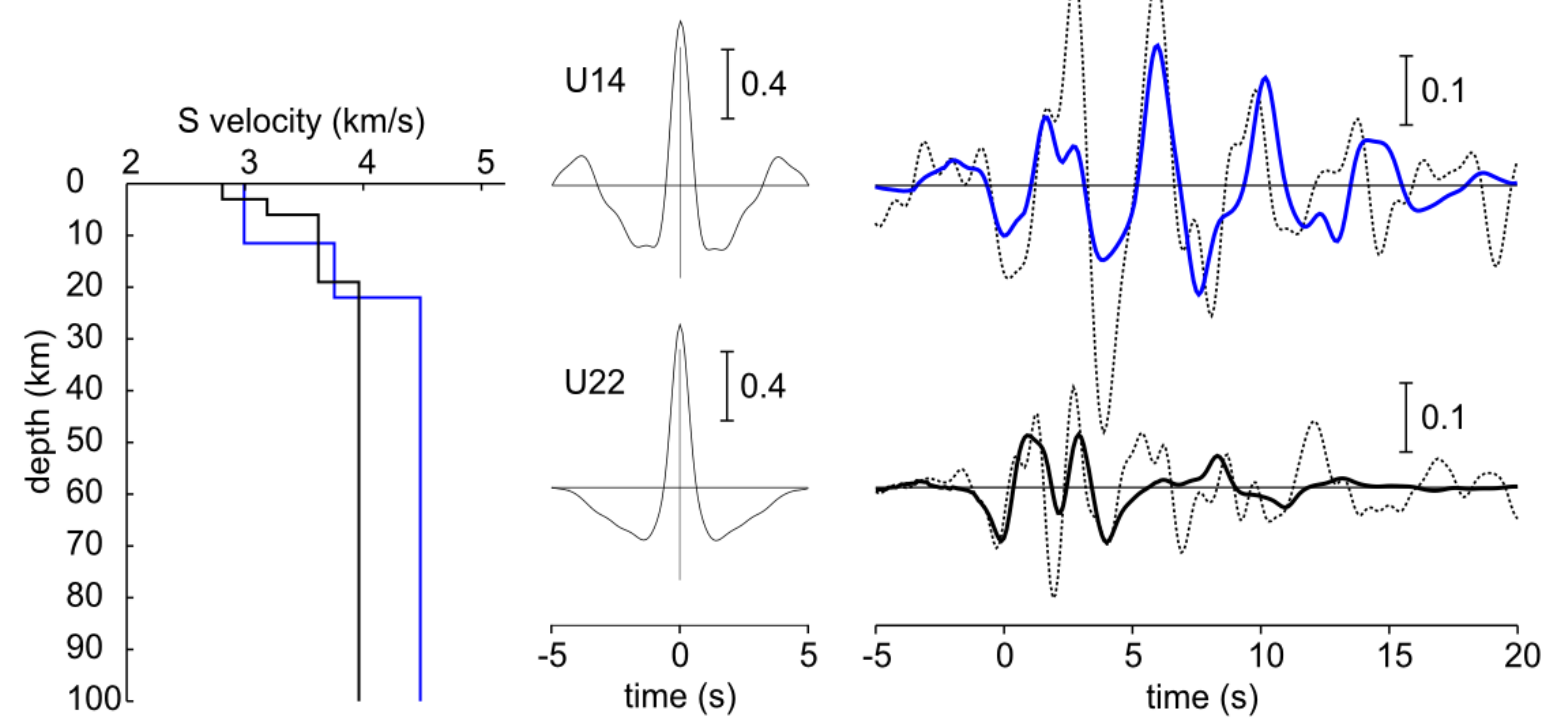

Figure S3: Forward modelling of synthetic receiver functions by the inversion algorithm of Kosarevet al. (1993) for the stations U14 and U22. We assume simple crustal models in order to fit the synthetic receiver functions (coloured lines) to the observed receiver functions (dotted black lines). This initial modelling leads to a sufficient fit of the receiver functions for the station U14 (upper panel). Specifically, the strong signal arriving at about 6s can be explained as a multiple phase from the discontinuity at about $12 \mathrm{~km}$ depth. In case of station U22 (lower panel), we are not able to explain the phases at delay times of about $5 \mathrm{~s}$ and $12 \mathrm{~s}$ by multiples of intracrustal discontinuities. These phases seem to be direct converted phases of additional deeper discontinuities within the lithospheric mantle. 


\section{Determination of sediment layer thicknesses}

To estimate the thickness of sediment layers in the Rwenzori area we used S-to-P conversions from the sedimentary base, visible in local earthquake records. In the figure below, we present a typical seismogram of a local earthquake recorded at station U01. The Sp phase is clearly identified, preceding the S wave by $2.2 \mathrm{~s}$. Significant amplitudes of the converted phase are restricted to the Z-component due to the near-vertical incidence. For each station within the rift valley we compiled a set of up to 10 records of local events and determined the travel-time differences between S and Sp. The results are presented in the table below. The average precursor times vary between $0.52 \mathrm{~s}$ (station U15) and $2.22 \mathrm{~s}$ (station U01). The standard deviations are remarkably small and correspond to the estimated picking accuracy for S-waves (ca. $\pm 0.1 \mathrm{~s}$ ).

To calculate layer thicknesses from the measured precursor times we assumed $\mathrm{v}_{\mathrm{P}}=3.0 \mathrm{~km} / \mathrm{s}$ and $\mathrm{v}_{\mathrm{S}}=1.6 \mathrm{~km} / \mathrm{s}$ for the sediments. These values were derived from studies in the Kenya rift (Henry et al. 1990). The results are presented in column 3 of the table below $\left(h_{1}\right)$. The calculated sediment thicknesses range from $1.6 \mathrm{~km}$ beneath station U15 to $6.6 \mathrm{~km}$ beneath station U01. To test the influence of the assumed velocities on the resulting sediment thickness we applied additionally values that were derived by Mandal (2007) for the Kachchh rift basin, India. These velocities are relatively small $\left(\mathrm{v}_{\mathrm{P}}=2.9 \mathrm{~km} / \mathrm{s}, \mathrm{v}_{\mathrm{S}}=0.9 \mathrm{~km} / \mathrm{s}\right)$ with an extreme $\mathrm{v}_{\mathrm{P}} / \mathrm{v}_{\mathrm{S}}$ ratio of 3.2 and lead to significant thinner sediment layers $\left(h_{2}\right.$ in the table below). However, our initial results $\left(h_{1}\right)$ show sediment layers of $\sim 6 \mathrm{~km}$ close to the Lake Albert area (station U01) which correlates much better with the observations of Karneret al. (2000) than the $\mathrm{h}_{2}$ results. We used these velocities and sediment thicknesses to consider their effect on the derived Moho depths.

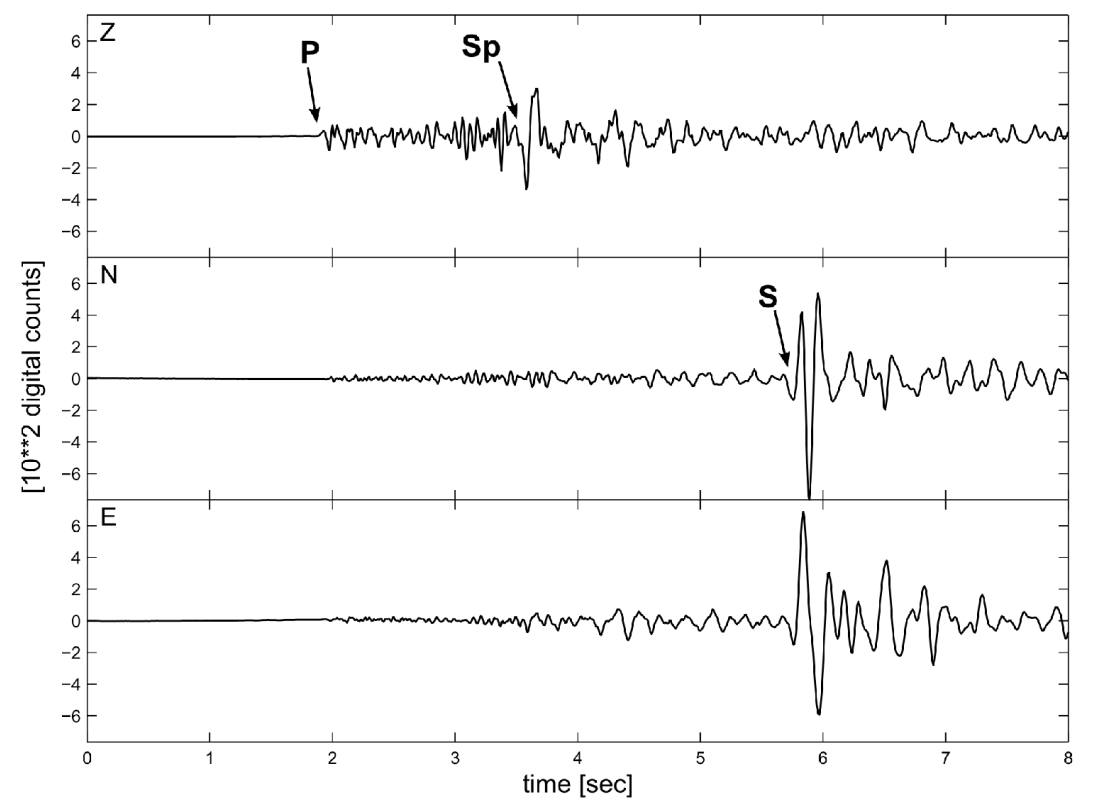

Figure S4: Seismogram of a local earthquake (raw data, not filtered), recorded at station U01 $(\mathrm{ML}=2.0$, depth = $14 \mathrm{~km}$, distance $=12 \mathrm{~km}$ ). P- and S-waves are marked. The S-precursor, Sp, is used to estimate the thickness of the sediment layer beneath the station. 


\begin{tabular}{cccc}
\hline Station & $\mathrm{t}_{\mathrm{s}}-\mathrm{t}_{\mathrm{sp}}(\mathrm{sec})$ & $\mathrm{h}_{1}(\mathrm{~km})$ & $\mathrm{h}_{2}(\mathrm{~km})$ \\
\hline C04 & $0.64 \pm 0.05$ & $1.93 \pm 0.12$ & $0.78 \pm 0.05$ \\
C09 & $0.77 \pm 0.12$ & $2.38 \pm 0.49$ & $0.94 \pm 0.18$ \\
U01 & $2.22 \pm 0.13$ & $6.59 \pm 0.48$ & $2.64 \pm 0.19$ \\
U02 & $1.10 \pm 0.18$ & $3.37 \pm 0.53$ & $1.34 \pm 0.22$ \\
U03 & $0.86 \pm 0.07$ & $2.50 \pm 0.23$ & $1.00 \pm 0.10$ \\
U08 & $0.97 \pm 0.13$ & $2.93 \pm 0.41$ & $1.16 \pm 0.16$ \\
U09 & $0.79 \pm 0.04$ & $2.53 \pm 0.14$ & $0.99 \pm 0.05$ \\
U14 & $1.51 \pm 0.20$ & $4.57 \pm 0.72$ & $1.83 \pm 0.29$ \\
U15 & $0.52 \pm 0.09$ & $1.62 \pm 0.29$ & $0.64 \pm 0.11$ \\
U19 & $1.44 \pm 0.10$ & $4.48 \pm 0.39$ & $1.76 \pm 0.15$ \\
\hline
\end{tabular}

Table S1: Sediment layer thicknesses $\left(\mathrm{h}_{1}, \mathrm{~h}_{2}\right)$ derived from converted Sp-phases assuming two different velocity models.

- $\mathrm{t}_{\mathrm{s}}-\mathrm{t}_{\mathrm{sp}}$ : observed travel-time differences of $\mathrm{S}$ and Sp phases

- $\mathrm{h}_{1}$ : sediment thicknesses calculated with $\mathrm{v}_{\mathrm{p}}=3.0 \mathrm{~km} / \mathrm{s}$ and $\mathrm{v}_{\mathrm{s}}=1.6 \mathrm{~km} / \mathrm{s}$, derived from results in the Kenya rift (Henry et al. 1990).

- $\quad \mathrm{h}_{2}$ : sediment thicknesses calculated with $\mathrm{v}_{\mathrm{P}}=2.9 \mathrm{~km} / \mathrm{s}$ and $\mathrm{v}_{\mathrm{s}}=0.9 \mathrm{~km} / \mathrm{s}$, Kachchh rift basin, India (Mandal 2007) 
a)
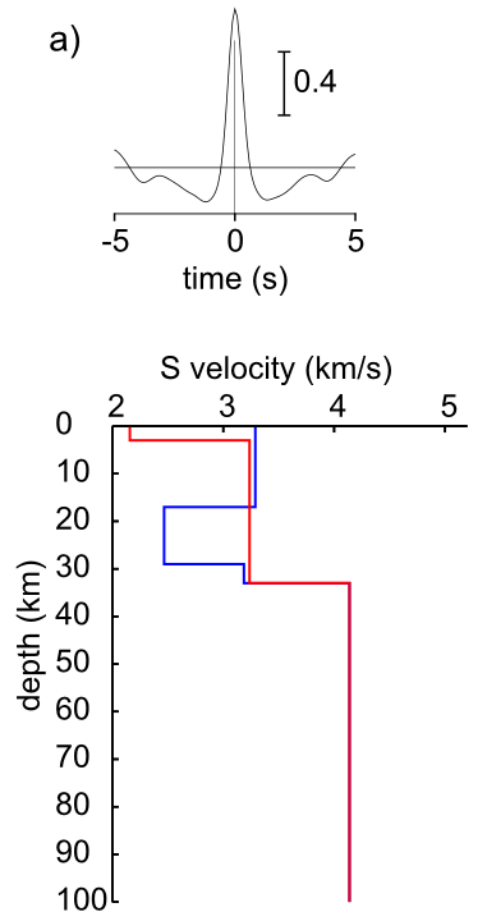

b)

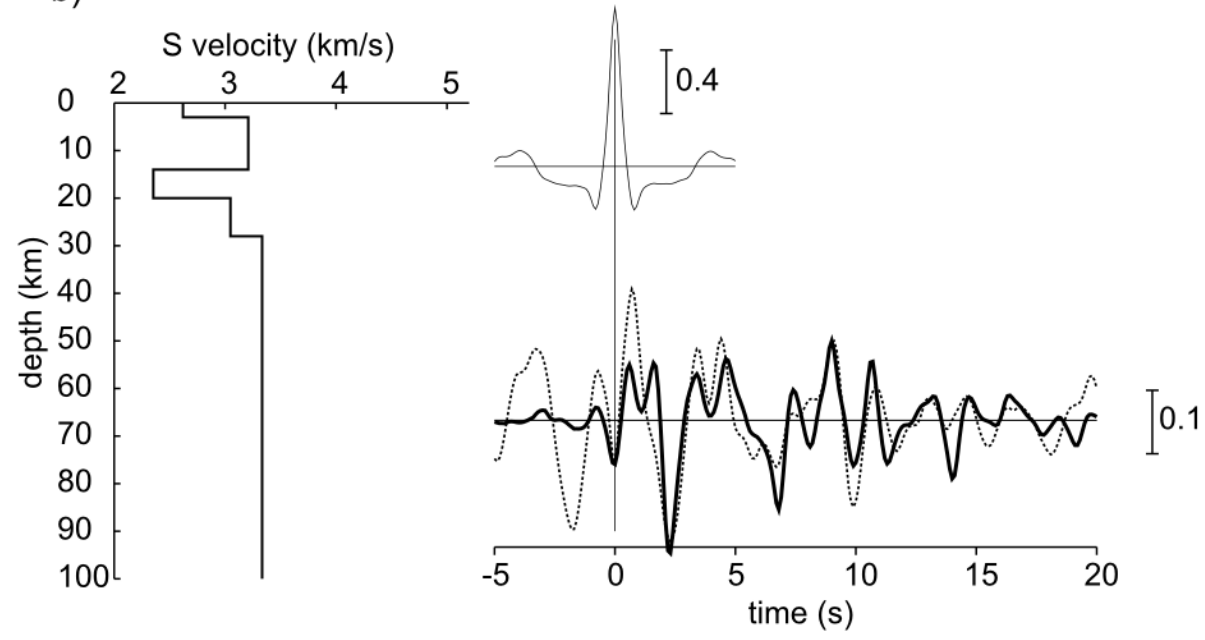

Figure S5: Modelling of receiver functions by the inversion algorithm of Kosarevet al. (1993). (a) For station U08 we consider 3 simple cases of the S velocity profiles in the crust: the first model exhibits a sediment layer (red line), the second model exhibits a $10 \mathrm{~km}$ thick low velocity layer (blue line),the third model is a combination of the previous models (results are given by the thick black line). The best fit between observed (dotted black line) and calculated receiver functions (coloured lines) is obtained for the combined model. (b) Observed and calculated receiver function for station U03. 


\section{References cited in the supplementary information}

Henry, W. J., Mechie, J., Maguire, P.K.H., Khan, M.A., Prodehl, C., Keller, G.R., and Patel, J. 1990. A seismic investigation of the Kenya Rift Valley.Geophysical Journal International, 100, 107-130

Karner, G. D., Byamungu, B. R., Ebinger, C. J., Kampunzu, A. B., Mukasa, R. K., Nyakaana, J., Rubondo, E. N. T., and Upcott, N. M. 2000. Distribution of crustal extension and regional basin architecture of the Albertine rift system, East Africa.Marine and Petroleum Geology, 17, 1131-1150

Kennett, B. L. N. andEngdahl, E. R. 1991. Traveltimes for global earthquake location and phase identification.Geophysical Journal International, 105, 429-465

Kosarev G. L., Petersen S. V., Vinnik L. P., Roecker S. W. 1993. Receiver functions for the Tien Shan analog broadband network: contrasts in the evolution of structures across the Talasso-Fergana fault. J.Geophys. Res.,98, 4437-4448.

Mandal, P. 2007. Sediment Thicknesses and Qs vs. Qp Relations in the Kachchh Rift Basin, Gujarat, India Using Sp Converted Phases. Pure appl. geophys.,164, 135-160

Zhu, L. and Kanamori, H. 2000. Moho depth variation in southern California from teleseismic receiver functions. Journal of Geophysical Research-Solid Earth, 105, 2969-2980, doi: 10.1029/1999JB900322 